\title{
Chagas' Heart Disease: Evolutive Evaluation of Electrocardiographic and Echocardiographic Parameters in Patients with the Indeterminate Form
}

\author{
Barbara Maria lanni, Edmundo Arteaga, Clovis de Carvalho Frimm, Antonio Carlos Pereira Barretto, \\ Charles Mady
}

São Paulo, SP - Brazil

Objective - To identify and associate potential electrocardiographic and echocardiographic changes in patients with the indeterminate form of Chagas' disease during long-term follow-up.

Methods - One hundred sixty patients underwent standard electrocardiography and two-dimensional guided M-mode echocardiography for left ventricular ejection fraction determination. Patients were followed up for $98.6 \pm 30.4$ months, undergoing repeat electrocardiographic studies at 6-month intervals and echocardiographic studies at 12-month intervals.

Results - Based on the electrocardiographic findings, the patients were divided into group I, 125 patients (78.6\%) with normal electrocardiograms throughout follow-up, and group II, 34 patients (21.3\%) who developed electrocardiographic changes. Group II was further divided into group IIA (9 patients, 5.6\%) with permanent electrocardiographic changes, group IIB (14 patients, 8.8\%) with transitory electrocardiographic changes, and group IIC (11 patients, 6.9\%) with changes appearing only on the final electrocardiogram. Left ventricular ejection fractions remained normal in the entire population studied and did not differ among groups.

Conclusion - The indeterminate form of Chagas' disease clearly represents a benign condition with a favorable long-term prognosis. Although some patients develop electrocardiographic changes, left ventricular systolic function is well preserved.

Key words: Chagas' heart disease, electrocardiographic changes, ejection fraction

Heart Institute (InCor) HC-FMUSP, University of São Paulo Medical School Mailing address: Barbara Maria Ianni - InCor - Divisão Clínica, Equipe de Cardiopatias Gerais - Av. Dr. Enéas C. Aguiar, 44 - 05403-900 - São Paulo, Brasil - e-mail: barbara.ianni@incor.usp.br

Received to publication in $19 / 7 / 00$

Accepted in 10/1/01
Chagas' disease is an important public health disorder in Latin America. It is an infectious disease caused by the protozoan parasite, Trypanosoma cruzi, which is transmitted zoonotically. Infection may occur following skin contact with the excrement of different strains of Triatoma insects, which serve as a vector. The parasite can multiply and transform within the Triatoma insect following ingestion via blood meal from an infected host. Chagas' disease is a chronic disease characterized by cardiovascular and gastrointestinal involvement. After an often-unrecognized acute phase followed by a generally undetected and lengthy latent period, cardiac symptoms and dysfunction of the esophagus, the colon, or both may develop.

Data from the World Health Organization state that $25 \%$ of the population in Latin American countries, approximately 90 million people, are exposed to this disease. As a consequence, it is estimated that as many as 16 million people are infected ${ }^{1}$.

In Brazil, the endemic area is estimated to be around 3.6 million $\mathrm{km}^{2}$, the largest in South America ${ }^{2,3}$. According to published data, 5 to 6 million people in this region are infected ${ }^{2,3}$. Studies in endemic areas show that 25 to $35 \%$ of the infected population manifests cardiac symptoms, with severe myocardial damage in $10 \%$. As many as 6000 cardiac deaths are reported each year ${ }^{4}$.

However, it has been known since Carlos Chagas' pioneering studies ${ }^{5}$ that up to $60 \%$ of infected patients have no evidence suggesting cardiovascular or gastrointestinal involvement. These individuals are thought to have what is known as the indeterminate form of the disease. The longterm outcome in these patients has not been clearly determined. Although longitudinal follow-up studies have demonstrated the development of electrocardiographic changes in some ${ }^{6,7}$, these changes do not seem to modify the prognosis. As a result, survival in this group of patients appears comparable to that of the general population ${ }^{3,8-11}$. The reason for the lack of a detectable impact of these ongoing 
electrocardiographic changes on patient prognosis (i.e. the favorable prognosis) is unclear ${ }^{7}$. We hypothesized that these changes are not accompanied by myocardial dysfunction.

The objective of this study was to prospectively evaluate patients with the indeterminate form of Chagas' disease and relate the likely appearance of electrocardiographic changes during follow-up to potential changes in left ventricular function.

\section{Methods}

We studied 160 patients with the indeterminate form of Chagas' disease from 1979 until 1994, encompassing a mean follow-up interval of $98.6 \pm 30.4$ months. The population included 98 women and 62 men, ranging in age from 17 to 61 years, with a mean age of $36.5 \pm 8.8$ years. A diagnosis of the indeterminate form was made in asymptomatic patients based on the presence of two positive serologic tests for Chagas' disease in combination with a normal electrocardiogram and chest radiograph with no evidence of cardiac enlargement. Barium studies of the esophagus and the colon in such patients are also normal ${ }^{12,13}$.

Subjects represented individuals from the general population in whom serologic tests were performed prior to blood donation. They came from endemic areas and were living in São Paulo. To assure that they were not reinfected after enrollment, none of them returned to their former homes. This study was approved by the Ethics Committee at our institution. All patients were educated about the objectives of the study and provided written informed consent.

Clinical follow-up was performed at a 3-month interval, and the same cardiologist always conducted the outpatient visits. Standard electrocardiograms were performed at sixmonth intervals and were analyzed independently by two cardiologists. Determinations of electrocardiographic changes were based on internationally recognized criteria ${ }^{14}$.

Annual M-mode two-dimensional guided echocardiography was performed with 2.5 to $3.5 \mathrm{MHz}$ transducers and standard equipment. Tracings were recorded on strip chart paper at $50 \mathrm{~m} . \mathrm{s}^{-1}$. Left ventricular internal dimensions at endsystole and end-diastole were obtained with the help of simultaneous electrocardiographic registration, according to the recommendations of the American Society of Echocardiography ${ }^{15}$. End-systolic and end-diastolic volumes, and the corresponding ejection fraction, were calculated based on the cube method for left ventricular volume determination ${ }^{16}$.

$\mathrm{LVEF}_{3}$, the ejection fraction corresponding to the echocardiogram obtained at the end of the study, was compared with the $\mathrm{LVEF}_{1}$ obtained during enrollment. In addition to the annual studies, a supplemental echocardiogram was obtained, and the $\mathrm{LVEF}_{2}$ was determined, whenever an electrocardiographic change was detected.

Statistical analysis of the data was performed using the analysis of variance for repeated measures. An a value of 0.05 was chosen to establish significant differences. Statistical calculations were made using SAS software ${ }^{17}$.

\section{Results}

Only one patient was excluded from the study because of having suffered an acute myocardial infarction 104 months following enrollment. A total obstruction of the anterior descending coronary artery was demonstrated angiographically before successful thrombolysis.

Based on electrocardiographic changes, the remaining 159 patients were classified into two groups: group I and group II. Group I corresponded to 125 patients (78.6\%) without changes on follow-up electrocardiograms. It included 78 women, ranging from 20 to 57 years in age, with a mean age of $36.0 \pm 8.3$ years. Group II consisted of 34 patients $(21.3 \%)$ with electrocardiographic changes that developed during the follow-up interval. It included 20 women, ranging from 17 to 61 years, with a mean age of $38.2 \pm 10.4$ years. The total period of follow-up in group I averaged $97.5 \pm 28.5$ months (range: 48 to 175 months) and in group II averaged $102.8 \pm 36.8$ months (range: 48 to 177 months).

Group II was further divided into three additional subgroups: group IIA, 9 patients $(5.6 \%)$, with permanent electrocardiographic changes; group IIB, 14 patients (8.8\%), with transitory electrocardiographic changes; and group IIC, 11 patients $(6.9 \%)$ in whom the electrocardiographic changes appeared only at the final evaluation period. The types of electrocardiographic alteration are summarized in Table I.

Table II depicts mean ages within subgroups. As can be seen, group IIA and group IIC patients were older than group IIB and group I patients ( $\mathrm{p}=0.0008)$.

Table III shows the ejection fractions determined via echocardiography for the entire population studied. These ejection fractions did not significantly change during follow-up, either in group I or in any of the three group II subgroups. Initial $\left(\mathrm{LVEF}_{1)}\right.$ and final $\left(\mathrm{LVEF}_{3}\right)$ ejection fractions were similar between group I and group II patients. Furthermore, ejection fractions determined in group II patients close to the appearance of an electrocardiographic change $\left(\mathrm{LVEF}_{2}\right)$ did not statistically differ from those obtained either at the beginning or end of the study.

\section{Discussion}

The results of the present study indicate that only a portion of patients with the indeterminate form of Chagas' disease develop significant electrocardiographic changes. Furthermore, these changes do not appear to be accompanied by corresponding left ventricular dysfunction.

Previous longitudinal studies of such patients have revealed percentages of electrocardiographic changes ranging from $23 \%$ to $38 \%$ during long-term follow-up ${ }^{7,8}$. Thus, our present results, showing electrocardiographic abnormalities in up to $21 \%$ of the studied subjects, are in accordance with the literature. However, it has to be emphasized that electrocardiographic abnormalities that could have been clearly attributed to Chagas' disease existed in only 15 of 34 group II patients. This was particularly the case in those who developed conduction defects like an isolated right bundle-branch 


\begin{tabular}{|c|c|c|}
\hline & Electrocardiographic changes & $\mathrm{N}^{\circ}$ patients (\%) \\
\hline \multirow[t]{8}{*}{ Group IIA } & Isolated right bundle-branch block & $2(1.2)$ \\
\hline & Right bundle-branch block associated to left anterior fascicular block & $1(0.6)$ \\
\hline & Left bundle-branch block & $1(0.6)$ \\
\hline & Complete atrioventricular block & $1(0.6)$ \\
\hline & Anteroseptal electrically inactive area & $1(0.6)$ \\
\hline & Isolated supraventricular extrasystoles & $1(0.6)$ \\
\hline & Displacement of QRS axis to the left without left anterior fascicular block & $1(0.6)$ \\
\hline & $\mathrm{T}$ wave changes & $1(0.6)$ \\
\hline \multirow[t]{10}{*}{ Group IIB } & $\mathrm{T}$ wave changes & $3(1.8)$ \\
\hline & Junctional rhythm & $3(1.8)$ \\
\hline & Isolated supraventricular extrasystoles & $1(0.6)$ \\
\hline & Isolated ventricular extrasystoles & $1(0.6)$ \\
\hline & Ventricular bigeminism & $1(0.6)$ \\
\hline & Wandering pacemaker & $1(0.6)$ \\
\hline & Acute atrial fibrillation & $1(0.6)$ \\
\hline & First degree atrioventricular block & $1(0.6)$ \\
\hline & Incomplete right bundle branch block & $1(0.6)$ \\
\hline & Displacement of QRS axis to the left without left anterior fascicular block & $1(0.6)$ \\
\hline \multirow[t]{5}{*}{ Group IIC } & $\mathrm{T}$ wave changes & $5(3.0)$ \\
\hline & Isolated ventricular extrasystoles & $3(1.8)$ \\
\hline & Ventricular bigeminism & $1(0.6)$ \\
\hline & Right bundle-branch block & $1(0.6)$ \\
\hline & Inferior electrically inactive area & $1(0.6)$ \\
\hline
\end{tabular}

\begin{tabular}{|lcc|}
\hline \multicolumn{3}{|c|}{ Table II - Mean ages of patients with indeterminate form of } \\
Chagas' disease by group \\
\hline Group & $\mathrm{N}^{\circ}$ of patients & Age (years) \\
\hline I & 125 & $36.0 \pm 8.3$ \\
IIA & 9 & $46.4 \pm 4.5^{*}$ \\
IIB & 14 & $32.4 \pm 8.7$ \\
IIC & 11 & $39.1 \pm 11.3 *$ \\
& & $* \mathrm{p}=0.0008$ \\
\hline \multirow{2}{*}{$* \mathrm{p}=0.0008$; significant increase compared with group I and group IIB. } \\
\hline
\end{tabular}

\begin{tabular}{|c|c|c|c|c|}
\hline \multicolumn{5}{|c|}{ Table III - Evolutive echocardiographic ejection fraction } \\
\hline \multicolumn{2}{|c|}{ Group $\mathrm{N}^{\circ}$ of patients } & \multirow{2}{*}{$\frac{\mathrm{LVEF}_{1}{ }^{*}}{0.73 \pm 0.05}$} & \multirow{2}{*}{$\frac{\mathrm{LVEF}_{2}}{-}$} & \multirow{2}{*}{$\frac{\mathrm{LVEF}_{3}^{*}}{0.74 \pm 0.04}$} \\
\hline I & 125 & & & \\
\hline IIA & 9 & $0.73 \pm 0.03$ & $0.71 \pm 0.08$ & $0.73 \pm 0.07$ \\
\hline IIB & 14 & $0.72 \pm 0.04$ & $0.73 \pm 0.06$ & $0.72 \pm 0.08$ \\
\hline \multirow[t]{2}{*}{ IIC } & 11 & $0.73 \pm 0.04$ & $0.71 \pm 0.03$ & $0.71 \pm 0.03$ \\
\hline & - & $\mathrm{p}=0.6886$ & $\mathrm{p}=0.7474$ & $\mathrm{p}=0.0601$ \\
\hline \multicolumn{5}{|c|}{$* \mathrm{p}=0.6698$} \\
\hline \multicolumn{5}{|c|}{$\begin{array}{l}\mathrm{LVEF}_{1} \text { - initial left ventricular ejection fraction; } \mathrm{LVEF}_{2}-\text { left ventricular } \\
\text { ejection fraction determined close to the appearance of an ECG change; } \\
\mathrm{LVEF}_{3} \text { - final left ventricular ejection fraction. }\end{array}$} \\
\hline
\end{tabular}

block, right bundle- branch block accompanied by left anterior divisional block, left bundle-branch block, eventual highdegree atrioventricular blockade, or all of these. Despite this, all electrocardiographic abnormalities were taken into account in the present analysis, including the nonspecific ones commonly reported in the general population ${ }^{3,6,8,11,18-28}$. This likely led to an overestimate of the frequency of electrocardiographic changes herein reported.
Echocardiographic data on indeterminate form patients are numerous, but sometimes conflicting, due to a generalized lack of strict criteria used to characterize this latent form of the disease. Many reports include patients with only minor electrocardiographic changes, which likely represent mild, but true, myocardial damage ${ }^{29,30}$. This may explain some earlier reports of either segmental ${ }^{30}$ or diffuse impairment of left ventricular contractility ${ }^{32,33}$.

However, data are lacking on long-term echocardiographic function in patients with the indeterminate form of the disease. To the best of our knowledge, the sole study published in this regard documented the development of global left ventricular systolic dysfunction in a small number of patients with previously documented diastolic dysfunction ${ }^{34}$. To date, the presence of diastolic dysfunction does not rule out the diagnosis of the indeterminate form of Chagas' disease, which is based solely on electrocardiographic criteria, as already stated. Indeed, it is conceivable that diastolic dysfunction could represent the initial stage of myocardial damage, and antedate global left ventricular systolic dysfunction. Unfortunately, diastolic properties were not systematically evaluated in our study from the beginning. However, the most recent echocardiograms performed in our patients did not show changes in diastolic function (data not shown), indicating that diastole was not initially impaired. As a consequence, this may explain the lack of evolving systolic dysfunction in our patients in contrast with the findings in the previously reported study.

Interestingly, patients with permanent electrocardiographic changes or changes observed only at the final evaluation, were older than those with or without transitory abnormalities. Whether or not the changes observed on the final electrocardiographic examination represent permanent 
or only transitory changes awaits further evaluation. It is likely, however, that because these changes developed late, and in older subjects, they may be permanent. Nevertheless, the time-related appearance of electrocardiographic abnormalities suggests that the evolution of the indeterminate form of Chagas' disease is influenced by patient age.

On the other hand, the present results clearly suggest that patients with the indeterminate form of Chagas' disease, in general, have a very good prognosis. The factors related to this favorable outcome have yet to be determined, but a normal ejection fraction despite electrocardiographic changes may be relevant in this regard.
Unfortunately, it is a common practice in our country to perform serological tests for Chagas' disease as part of the clinical evaluation for employment admission. Subjects with positive results are often relegated and have difficulty getting hired, even when applying for bureaucratic jobs. We hope that the present results will contribute to a better understanding of this form of Chagas' disease and reverse this situation. Our view is that these subjects should be advised not to exclude themselves from normal daily activities and that they are fully able to apply for and to perform all kinds of jobs, including those requiring muscle strength.

\section{References}

1. World Health Organization. Control of Chagas' disease. Report of the WHO Expert Committee. Geneva. WHO Technical Report Series 1991; 811: 1-95.

2. Dias JCP, Dias E. Doença de Chagas'. In: Brasil. Ministério da Saúde - SUCAM. Doença de Chagas: texto de apoio. Brasília, 1989: 13-20.

3. Maguire JH, Hoff R, Sherlock I, et al. Cardiac morbidity and mortality due to Chagas' disease: prospective electrocardiographic study of a Brazilian community. Circulation 1987; 45: 1140-5.

4. Brasil. Ministério da Saúde. Estatísticas de Mortalidade. Brasília, 1987.

5. Chagas C. Processos patogênicos da tripanosomíase americana. Mem Inst Oswaldo Cruz (Rio de Janeiro) 1916; 8: 7-36.

6. Laranja FS, Dias E, Nóbrega E, Miranda A. Chagas' disease: a clinical, epidemiologic, and pathologic study. Circulation 1956; 14: 1035-60.

7. Dias JCP. História natural. In: Cançado JR, Chuster M - Cardiopatia chagásica. Belo Horizonte, Fundação Carlos Chagas, 1985: cap.11: 99-113.

8. Coura JR, Abreu LL, Pereira JB, Willcox HP. Morbidade da doença de Chagas: IV - Estudo longitudinal de dez anos em Pains e Iguatama, Minas Gerais, Brasil. Mem Inst Osw Cruz 1985; 80: 73-80.

9. Carrasco HA, Parada H, Guerrero L, Duque M, Durán D, Molina C. Prognostic implications of clinical, electrocardiographic and hemodynamic findings in chronic Chagas' disease. Intern J Cardiol 1994; 43: 27-38.

10. Espinosa R, Carrasco HA, Belandria F, et al. Life expectancy analysis in patients with Chagas' disease: prognosis after one decade (1973-1983). Intern J Cardiol 1985; 8: 45-56.

11. Pereira JB, Willcox HP, Coura JR. Morbidade da doença de Chagas. III. Estudo longitudinal de 6 anos em Virgem da Lapa, Minas Gerais, Brasil. Mem Inst Osw Cruz 1985; 80: 63-71.

12. Camargo ME, Oshino-Shimizu S, Macedo V, Peres BA, Castro C. Diagnóstico sorológico da infecção humana pelo Trypanosoma cruzi. Estudo comparativo de testes de fixação do complemento, imunofluorescência, hemaglutinação e floculação em 3.624 soros. Rev Inst Med Trop São Paulo 1977; 19: 254-60.

13. Primeira Reunião de Pesquisa Aplicada em Doença de Chagas. Validade do conceito da forma indeterminada. Rev Soc Bras Med Trop 1985; 18: 46.

14. Cookey JD, Dunn M, Massie E. Clinical Vectorcardiography and Electrocardiography. $2^{\text {nd }}$ ed. Chicago: Year Book Medical Publishers Inc., 1977.

15. Sahn DJ, DeMaria NA, Kisslo J, Weyman A. The Committee on M-mode Standardization of the American Society of Echocardiography. Recommendations regarding quantitation in M-mode echocardiography: results of a survey of echocardiographic measurements. Circulation 1978; 58: 1072-83.

16. Pombo JF, Troy BL, Russell Jr. RO. Left ventricular volumes and ejection fraction by echocardiography. Circulation 1971; 43: 480-90.

17. Timm NH. Multivariate analysis with applications in education and psychology. Monterey, California: Brooks/Cole Publishing Company, 1975: 444-59.
18. Porto CC. O eletrocardiograma no prognóstico e evolução da doença de Chagas. Arq Bras Cardiol 1964; 17: 313-46.

19. Dias JCP, Kloetzel K. The prognostic value of the electrocardiographic features of chronic Chagas' disease. Rev Inst Med Trop São Paulo 1968; 10: 158-62.

20. Mady C, Cardoso RHA, Pereira-Barretto AC, Luz PL, Bellotti G, Pileggi F. Survival and predictors of survival in patients with congestive heart failure due to Chagas"' cardiomyopathy. Circulation 1994; 90: 3098-102.

21. Brasil A. A mutabilidade electrocardiográfica na cardiopatia crônica chagásica. Rev Assoc Med Minas Gerais 1953; 4: 149-52.

22. Hiss RG, Lamb LE. Electrocardiographic findings in 122,043 individuals. Circulation 1962; 25: 947-61.

23. Rotman N, Triebewasser JH. A clinical and follow-up study of right and left bundle branch block. Circulation 1975; 51: 477-84

24. Averill KH, Lamb LE. Electrocardiographic findings in 67,375 asymptomatic subjects. I. Incidence of abnormalities. Am J Cardiol 1960; 6: 76-83.

25. Grupi CJ, Sosa E, Carvalho JF, Antonelli RH, Bellotti G, Pileggi F. Variabilidade espontânea da extrassistolia ventricular na cardiopatia chagásica crônica. Arq Bras Cardiol 1991; 56: 445-50.

26. Fosmoe RJ, Averill KH, Lamb LE. Electrocardiographic findings in 67,375 asymptomatic subjects. Am J Cardiol 1960; 6: 84-95.

27. Pereira JB, Coura JR. Morbidade da doença de Chagas. Estudo seccional em uma área endêmica, Virgem da Lapa, MG. Rev Soc Bras Med Trop 1986; 19: 139-48.

28. Brodsky M, Wu D, Denes P, Kanakis C, Rosen KM. Arrhythmias documented by 24-hour continuous electrocardiographic monitoring in 50 male medical students without apparent heart disease. Am J Cardiol 1977; 39: 390-5.

29. Mady C, Pereira-Barretto AC, Ianni BM, Lopes EA, Pileggi F. Right ventricular endomyocardial biopsy in indeterminate form of Chagas' disease. Angiology 1984; 35: 755-9.

30. Pereira-Barretto AC, Mady C, Arteaga E, et al. Right ventricular endomyocardial biopsy in chronic Chagas' disease. Am Heart J 1986; 111: 307-12.

31. Ortiz J, Pereira-Barretto AC, Matsumoto A, et al. Alteração contrátil segmentar na forma indeterminada da doença de Chagas. Estudo ecocardiográfico. Arq Bras Cardiol 1987; 49: 217-20.

32. Friedmann AA, Armelin E, Nelken JR, Zerbini CAF, Coimbra MA, Serro-Azul LG. Estudo ecocardiográfico do desempenho ventricular em fase pré-clínica da doença de Chagas. Rev Hosp Clin Fac Med S Paulo 1980; 35: 165-70.

33. Friedmann AA, Armelin E, Leme LEG, et al. Desempenho ventricular na doença de Chagas. Relações ecocardiográficas na miocardiopatia com distúrbio dromótropo e na fase pré-clínica. Arq Bras Cardiol 1981; 36: 23-7.

34. Cunha CLP, Urbanetz LAGT, Souza AM, et al. Evolutive Doppler echocardiographic changes in the indeterminate phase of Chagas' disease. Eur Heart J 1993; $14: 135$. 